Revista de la red interuniversitaria de estudios sobre las literaturas rioplatenses contemporáneas en Francia

$14 \mid 2016$

Levrero

\title{
Ars levreriana
}

\section{Mariano García}

\section{OpenEdition}

Journals

\section{Edición electrónica}

URL: http://journals.openedition.org/lirico/2323

DOI: $10.4000 /$ lirico. 2323

ISSN: 2262-8339

Editor

Réseau interuniversitaire d'étude des littératures contemporaines du Río de la Plata

\section{Referencia electrónica}

Mariano García, « Ars levreriana », Cuadernos LIRICO [En línea], 14 | 2016, Publicado el 07 junio 2016, consultado el 25 septiembre 2020. URL : http://journals.openedition.org/lirico/2323 ; DOI : https:// doi.org/10.4000/lirico.2323

Este documento fue generado automáticamente el 25 septiembre 2020

\section{cc) (i) (2)}

Cuadernos LIRICO está distribuido bajo una Licencia Creative Commons Atribución-NoComercialSinDerivar 4.0 Internacional. 


\section{Ars levreriana}

Mariano García

\section{REFERENCIA}

Un silencio menos. Conversaciones compiladas por Elvio E. Gandolfo. Buenos Aires: Mansalva, 2013. 
1 En el contexto del vertiginoso crecimiento póstumo que ha tenido en los últimos años la figura y la literatura del uruguayo Jorge Mario Varlotta Levrero (1940-2004) no sorprende la publicación de una antología de las entrevistas hechas al autor, entrevistas que cubren un arco amplio, entre 1977 y la última, publicada ya muerto el autor, de 2007. Se trata por lo tanto de un lapso que permite conocer y acompañar la trayectoria de Mario Levrero casi una década después de sus comienzos hasta la época del reconocimiento de la crítica y del público.

2 Frente a una lectura continua y sucesiva de las entrevistas se percibe una continuidad de la voz, de las inflexiones, una forma de presentarse que no desmiente las palabras del compilador y responsable de cuatro de las entrevistas

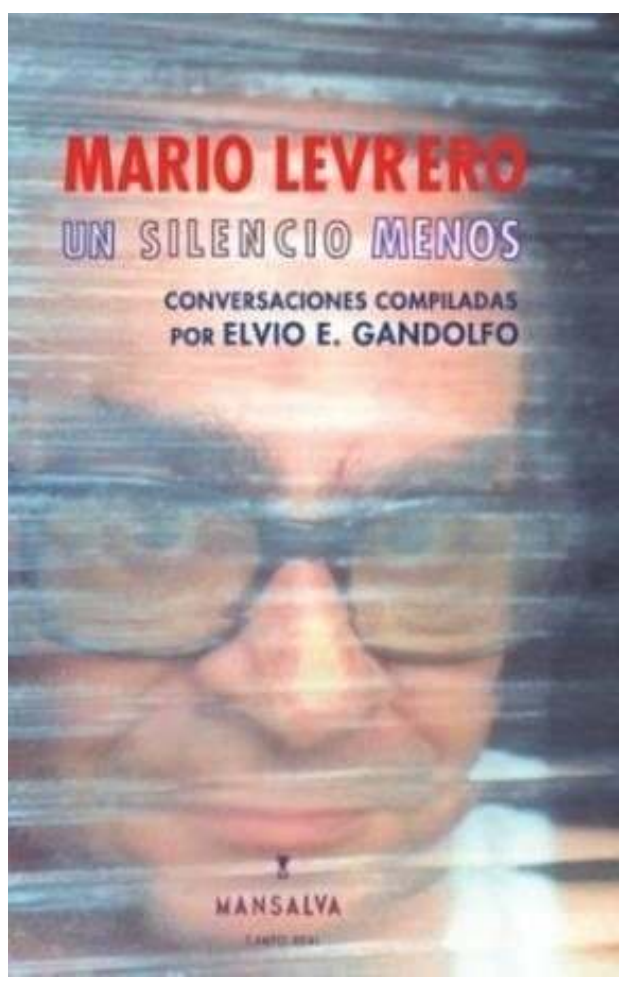
incluidas: se crea una atmósfera de cercanía en la que el lector se siente participar en el diálogo. Quizá se deba a que la figura de autor de Mario Levrero, esa figura que lleva a cabo precisamente tantas piruetas autoficcionales en su literatura, produce una sensación de honestidad y falta de artificio que lo destaca entre sus contemporáneos. Al mismo tiempo, ese tono que toca los registros de lo confesional, del buen y del mal humor, de la sinceridad como procedimiento (según la fórmula ya ensayada con rigor por Michel Leiris) se vuelve reconocible para el lector que viene de La novela luminosa, El discurso vacío o el "Diario de un canalla", donde el pacto de escritura consiste en una retórica de la ausencia de retórica que establece una firme complicidad en la recepción.

Sin duda, una obra en la que lo autoficcional no solo aparece de manera progresiva sino que socava incluso la pertinencia de esta categoría crítica tan asendereada, encuentra en estas entrevistas un complemento insoslayable, más allá del atractivo de la propia personalidad de Levrero, de la inteligencia de muchos de sus entrevistadores y por qué no, de esta especie de género, suerte de biografía múltiple y fragmentada que nos acerca de manera inmediata al autor pero también, por momentos, a la persona. $\mathrm{Y}$ eso, como veremos, no es en este caso indistinto.

De las varias líneas que podrían señalarse, todos los comentarios sobre su Yo autoral resultan de interés. Levrero es enfático a la hora de afirmar la identidad "real" con sus narradores, por más que a la vez esa identidad albergue replegada una teoría y una práctica del doble, según se desprende de la elocuente "Entrevista imaginaria con Mario Levrero", en la que el autor se desdobla en entrevistador y entrevistado. ${ }^{1}$ No escapa a su dualidad esencial la división de trabajo entre Jorge Varlotta y Mario Levrero, sumada a los múltiples seudónimos, todo lo cual se comenta en detalle a lo largo de estas páginas. Levrero llega a reconocer que tanto él como los críticos han manoseado demasiado a su figura de autor: "Es como si ese personaje que inventaron [los críticos] estuviera mirándome por encima del hombro para decirme "no, eso que 
estás haciendo no es de Levrero'. [...] Te van encasillando, encerrando en una especie de túnel, y tenés que responder a tus antecedentes o te sentís mal" (115). Según sus palabras, para Levrero toda su escritura es autobiográfica, solo que en una primera etapa lo autobiográfico aparece disimulado o enriquecido con símbolos, y en la última ya sin disfraces (163), pues para Mario Levrero la imaginación y los sueños son parte, y una parte esencial, de la realidad de una persona. En general el tema de la identidad y de los límites del yo estructura en buena medida la obra levreriana. Levrero insiste en que el escritor se forma en el momento de escribir, y en ese momento está en contacto (como aquel sismógrafo del que hablaba Aby Warburg) con otros estratos, núcleos o intereses del ser (118), algo que conecta directamente con sus intereses parapsicológicos y que, a fines del siglo $\mathrm{XX}$, lo vuelve una figura atípica aunque coherente con su defensa de la imaginación y de determinado tipo de percepción, como consta por su publicación en 1978 del Manual de parapsicología o su frecuentación de Jung, entre otras cosas.

5 Si hay temas que evolucionan, se transforman o desaparecen, su malhumor con la crítica es permanente y se muestra inmutable. Para Mario Levrero una verdadera obra de arte pone en peligro al receptor, pero la crítica, "policía del arte", se encarga de racionalizar y así, volver inofensivos esos productos originalmente revulsivos (192). Los críticos ejercen un poder destructivo pues "análisis implica destrucción" (123). Los críticos, "dueños de la realidad" (138) son asimilados por Mario Levrero a la dictadura; la crítica existe porque "en toda sociedad y en todo individuo están los gérmenes de una dictadura" (123).

6 Como es de esperar, lo más atrapante de la antología se cifra en los comentarios de Levrero sobre sus lecturas y sobre la escritura. En cuanto a esta última, hay una verdadera ars narrativa que se despliega particularmente en la entrevista de Pablo Silva Olazábal ${ }^{2}$ pero que no obstante aparece diseminada en buena parte de los reportajes. De esta serie se destaca su concepción enfáticamente no intertextual de la literatura (otro aspecto que lo diferencia de buena parte de los escritores contemporáneos) : la literatura no se nutre de la literatura, se nutre de la vida. Malgré Mallarmé, Levrero afirma : "Tenés que sacarte de la cabeza la idea de que se escribe a partir de la palabra, y sobre todo a partir de la invención intelectual" (173). Una de sus ideas más personales y más atractivas es la del arte como forma de hipnosis, que elabora a partir de la teoría del psicoanalista suizo Charles Baudouin. Hipnosis y sugestión bien empleadas pueden ser instrumentos de liberación, aunque para él la transmisión de la belleza se produce sobre todo a través de la poesía, en tanto que la narrativa expresa a través del vacío, de lo negativo, lo feo, lo regresivo, el pasado (17).

7 Hay muchos comentarios al pasar que encierran valiosas reflexiones, como sus observaciones sobre los géneros. Un texto que puede ser clasificado dentro de un subgénero posee una intención comercial, se dirige a determinado público. Ese tipo de literatura, de evasión (que él encuentra perfectamente lícita) se diferencia de otra literatura, de integración, de liberación de zonas reprimidas (45). Abundan los comentarios sobre su forma de escribir, similar a la escritura automática pero que Levrero prefiere llamar "psicografía", en donde su Yo consciente apenas ejerce un leve control, un estado de trance en el que deja aflorar "esa otra persona que escribe" (41).

8 Como bien dice Elvio Gandolfo en su prólogo, hay un hilo conductor a lo largo de estos reportajes y es su dilatada relación con lo que terminaría siendo La novela luminosa. Asistimos, al tener una visión cronológica de los reportajes, al desarrollo y 
transformaciones de este vasto proyecto que se convertiría en su opus magnum, en la suma de sus obsesiones y en el epítome de su juego con la figura de autor. También se revela en estas páginas la existencia de un doble de este texto, una "novela oscura" (32) que no es otra que Desplazamientos, que en varias ocasiones se siente obligado a defender de lo que considera una lectura poco comprensiva de ese texto para él fundamental.

9 Además de las buenas entrevistas de Gandolfo y de Carlos María Domínguez (una de las cuales, "Levrero para armar", analiza paso a paso el corpus levreriano), la notable entrevista de Cristina Siscar se centra en lo fantástico, en su gusto por algunos pocos autores de ciencia ficción (el asombroso Cordwainer Smith, Olaf Stapledon), y la de Helena Corbellini en el humor, aunque esta entrevista cae en un malentendido final que ilumina involuntariamente varios aspectos simultáneos: la esquiva concepción levreriana del humor, de la religión y de lo autobiográfico $(90)^{3}$.

Podrían apuntarse muchos otros aspectos que brotan y se multiplican en la conversación precisamente hipnótica de Levrero, pero basta con apuntar que, más allá de algunas inevitables repeticiones, se trata de un libro de fascinante lectura al que todo lector de Levrero, e incluso el que recién se asome a él, puede estar más que agradecido, así como a la labor de Gandolfo y a la iniciativa del editor, Francisco Garamona. Es necesario aclarar, como lo hace el prólogo, que no se trata de una recopilación exhaustiva y también comentar, como ya es costumbre en Mansalva, la molesta proliferación de erratas. Una cronología basada en la valiosa bibliografía de Pablo Rocca que venía en la edición de Arca de Nick Carter... cierra el indispensable volumen.

\section{NOTAS}

1. Cabe aclarar que, si bien se consigna como aparecida en El portero y el otro (en efecto, es el texto final de ese volumen de relatos de 1992), esta entrevista se publicó en el número 160-161 de la Revista Iberoamericana (jul-dic. 1992) dedicado a la literatura uruguaya y editado por Lisa Block de Behar, a quien Levrero dedica su autorreportaje. En la sección de entrevistas, Levrero aparece acompañado por Armonía Somers y Miguel Ángel Campodónico, uno de los que lo entrevista en el libro que reseñamos.

2. Pablo Silva Olazábal publicó también en 2013 unas interesantes aunque irregulares Conversaciones con Mario Levrero, en realidad una reedición ampliada de previas ediciones chilena y uruguaya. Silva Olazábal fue alumno de taller de Levrero y sus diálogos con él se centran en aspectos y problemas de la escritura.

3. Helena Corbellini publicaría en 2011 un artículo de referencia sobre lo que ella caracteriza como "trilogía luminosa", esto es, La novela luminosa, El discurso vacío y el "Diario de un canalla", serie que con gran acierto Álvaro Matus caracteriza como "autobiografía psíquica” (198). 


\section{AUTORES}

MARIANO GARCÍA

Conicet-UCA 